\title{
Effect of Microwave Roasting and Extraction Solvents on the Bioactive Properties of Coffee Beans
}

\author{
Ahmad Mohammad Salamatullah (D), ${ }^{1}$ Khizar Hayat, ${ }^{1}$ Fohad Mabood Husain, ${ }^{1}$ \\ Mohammed Asif Ahmed ${ }^{D},{ }^{1}$ Shaista Arzoo, ${ }^{1}$ Abdullah Mohammed Alghunaymi, ${ }^{1}$ \\ Abdulhakeem Alzahrani (D), ${ }^{1}$ Heba Kahlil Alyahya, ${ }^{1}$ Nawal Al-Badr, \\ and Mohammed Bourhia $\mathbb{D}^{2}$ \\ ${ }^{1}$ Department of Food Science \& Nutrition, College of Food and Agricultural Sciences, King Saud University, P. O. Box 2460, \\ Riyadh 11451, Saudi Arabia \\ ${ }^{2}$ Laboratory of Chemistry-Biochemistry, Environment, Nutrition and Health, Faculty of Medicine and Pharmacy, \\ Hassan II University, Casablanca 5696, Morocco
}

Correspondence should be addressed to Abdulhakeem Alzahrani; aabdulhakeem@ksu.edu.sa

Received 7 August 2021; Accepted 3 September 2021; Published 21 September 2021

Academic Editor: Alessandra Durazzo

Copyright $\odot 2021$ Ahmad Mohammad Salamatullah et al. This is an open access article distributed under the Creative Commons Attribution License, which permits unrestricted use, distribution, and reproduction in any medium, provided the original work is properly cited.

\begin{abstract}
Coffee is an intricate mixture of thousands of chemical compounds that are accountable for its flavor and aroma. Roasting is a key step in the processing of coffee beans. This study assessed the effect of microwave roasting (MW) and extraction solvents (ES) on the total polyphenol content, total flavonoid content, and antioxidant activity of coffee beans. The untreated and microwaveroasted (MR) coffee beans showed a total polyphenol content of 40.40 and $35.15 \mathrm{mg} \mathrm{GAE} / \mathrm{gm} \mathrm{DW}$, respectively, when methanol was used as the solvent for extraction. Similarly, for the untreated coffee beans, the methanol extracted coffee had a significantly $(p<0.05)$ higher total flavonoid content $(39.34 \mathrm{mg} \mathrm{CE} / \mathrm{g} \mathrm{DW})$ as compared to ethanol $(34.82 \mathrm{mg} \mathrm{CE} / \mathrm{g} \mathrm{DW})$. The obtained IC 50 for the untreated and microwave-roasted samples as extracted by methanol were 4.13 and $5.68 \mathrm{mg} / \mathrm{mL}$, respectively, while the $\mathrm{IC}_{50}$ values of untreated and microwave-roasted samples extracted by ethanol were 4.59 and $6.24 \mathrm{mg} / \mathrm{mL}$, respectively. Untreated coffee beans exhibited a higher reducing power (1.237) than that of the microwave-roasted ones (0.839) when extracted with methanol. Chlorogenic acid was the major (2.31-2.68\%) phenolic compound found in all the coffee samples whether it was untreated or microwave-roasted. Vanillin demonstrated the lowest $(0.118-0.166 \%)$ phenolic compound found in the coffee bean samples. These results might be helpful for obtaining the maximum health benefits from coffee.
\end{abstract}

\section{Introduction}

Plant-derived foods have been used since the dawn of humankind for promoting health and preventing diseases. People from different cultures worldwide have revered coffee not only for its aromatic compounds but also because of its stimulating and health-promoting properties [1]. In addition to being the world's most highly consumed beverage, coffee has high nutritional value [2]. Many countries grow coffee as a primary crop as well as a valuable commodity [3-5]. Even though studies have reported inconsistent results in connection with coffee consumption, the general consensus is that regular, moderate coffee consumption by healthy individuals is either benign or slightly beneficial [6-10]. Coffee health benefits include reduction in the risk of metabolic syndrome, and protection against noncommunicable diseases such as liver disease, diabetes, cancer, and Parkinson's disease [11-13]. Polyphenols are abundant micronutrients in our diets, and evidence for their role in the prevention of noncommunicable diseases is growing. The bioavailability of polyphenols in coffee differs from one type to another [14]. High amounts of antioxidants and bioactive compounds are found in coffee, and it is the major source of chlorogenic acid [15]. Intake of chlorogenic acid varies widely but may be very 
high, up to $800 \mathrm{mg} / \mathrm{d}$ among coffee drinkers [16]. A single cup of Arabica coffee contains around 70 to $200 \mathrm{mg}$ of chlorogenic acid [17]. Coffee contains a large number of bioactive compounds which are presented in Table 1 [18-20].

Raw coffee beans undergo a chemical transformation during roasting and various factors can influence the biochemical composition of the end product. These factors include but are not limited to the type of beans, method of preparation and degree of roasting [21,22]. The coffee roasting process creates a special aroma and taste [23]. In addition, aroma and flavor are affected by temperature and time and the roasting parameters of coffee [18]. Longer roasting of coffee influences the level of bioactive compounds [24]. In a study by Alkaltham, the total phenol content of green coffee beans was reduced by $13.59 \%$ and $16.66 \%$ on microwave and oven roasting respectively [25]. There is an inverse relationship between the degree of roasting and antioxidant content [26]. Thus, the coffee roasting process is a key factor for maintaining nutritional value [18]. The phytochemicals in the food matrix have the property of being soluble in specific solvents, although, there is no universally accepted procedure available for measuring the antioxidant and phenolic contents of food. This in turn increases the need for careful selection of the extracting solvent $[27,28]$. Coffee extraction is a process, which states to dissolving the soluble components of coffee beans powder in a liquid solvent. In a study on comparing the results from water and methanolic extracts of coffee from different countries, the highest amount of phenolics, caffeine, reducing power, ability to chelate $\mathrm{Fe} 2+$, inhibition of linoleic acid peroxidation, and inhibition of lipoxygenase was determined for a methanolic extract of coffee [29]. An efficient method of preserving the bioactive compounds is needed [30]. Solid-liquid extraction with different solvents or solidphase extraction (SPE) followed by high-performance liquid chromatography (HPLC) for the determination of phenolic compounds is reported [31]. HPLC is commonly used for the qualitative and quantitative determination of phenolic compounds in coffee beans and HPLC based methods use mainly $\mathrm{C} 18$ with $5 \mu \mathrm{m}$ particle size packing materials as the stationary phase [32]. A lot of studies have been conducted on coffee; thus, data on the effects of microwave roasting with different extraction solvents on the bioactivity of coffee grown in Saudi Arabia is hardly available. As a result, this study focused on analyzing the effect of microwave roasting (MW) and extracting solvents (ES) on the bioactivity of coffee beans. Therefore, the total polyphenol content (TPC), total flavonoid content (TFC), and antioxidant activity (AA) in terms of DPPH (2, 2-diphenyl-1-picryl-hydrazyl), reducing power, and identification of phenolic compounds will be detected.

\section{Materials and Methods}

2.1. Materials. Coffea arabica was obtained from the Jazan region located in the Kingdom of Saudi Arabia. The coffee beans were sun-dried until their moisture level reached $11.2 \%$ of the dry weight. The samples were then ground and
TABle 1: Composition of bioactive compounds of roasted coffee bean $[18-20]$.

\begin{tabular}{lc}
\hline Bioactive compound & Traditional roasted \\
\hline Caffeine & $526 \pm 1.97$ \\
Gallic & $117 \pm 0.57$ \\
Chlorogenic & $600 \pm 1.83$ \\
Quercetin & $7 \pm 0.03$ \\
Kaempferol & $6 \pm 0.04$ \\
Caffeic & $5 \pm 0.07$ \\
Salicylic & $12.1 \pm 0.16$ \\
Epigallocatechin gallate & $28 \pm 0.19$ \\
Quercetin-3-O-glucoside & $2.8 \pm 0.1$ \\
Kaempferol-3-O-glucoside & $35 \pm 0.15$ \\
Caffeoylquinic acid & $3530 \pm 0.02$ \\
Caffeine & $2840 \pm 0.00$ \\
Melanoidins & $2380 \pm 0.77$ \\
Trigonelline & $1000 \pm 0.00$ \\
Redutores & $100 \pm 0.00$ \\
Cafestol & $742 \pm 41$ \\
Nicotinic acid & $19 \pm 3$ \\
Kahweol & $465 \pm 18$ \\
\hline
\end{tabular}

${ }^{*}$ Results are expressed in means \pm standard deviation and given in $\mathrm{mg} / 100 \mathrm{~g}$ of sample.

passed through a 60 -mesh $(250 \mu \mathrm{m})$ sieve. Coffee bean powder $(4 \mathrm{~g})$ was heated using a microwave oven at $720 \mathrm{~W}$ for $6 \mathrm{~min}$. An unheated sample was used as a control.

2.2. Extraction of the Samples. Two grams of coffee bean powder was extracted with $20 \mathrm{~mL}$ of either $50 \%$ methanol or $50 \%$ ethanol using an ultrasonic bath at $\left(20^{\circ} \mathrm{C}\right)$ for $45 \mathrm{~min}$. Afterward, the sample mixture was centrifuged for 10 minutes at $3000 \mathrm{rpm}$ and the temperature of the machine was set at $20^{\circ} \mathrm{C}$. Finally, the obtained supernatant was filtered through filter paper (Whatman filter paper No. 2). The coffee bean extract $(\mathrm{CBE})$ was maintained at $4^{\circ} \mathrm{C}$ and used for antioxidant assays. Steps followed in preparation of coffee bean extract are presented in Figure 1.

2.3. Total Polyphenol Content. The method suggested by Hayat [33] was used to analyze TPC. In brief, $25 \mu \mathrm{L}$ of CBE was mixed with $1500 \mu \mathrm{L}$ of water. After this, $125 \mu \mathrm{L}$ undiluted Folin-Ciocalteu reagent was added to the mixture. After $1 \mathrm{~min}, 375 \mu \mathrm{L}$ of $20 \%$ sodium carbonate and $475 \mu \mathrm{L}$ of water were added and the mixture was incubated for $30 \mathrm{~min}$ at $23^{\circ} \mathrm{C}$. Finally, the absorbance of the mixtures was read at $760 \mathrm{~nm}$ and the result was represented as $\mathrm{mg}$ gallic acid equivalent per gram dry matter (mg GAE/g DW).

2.4. Total Flavonoid Content. The procedure used by Hayat [33] was followed for analyzing TPC in CBE. Two hundred and fifty $\mu \mathrm{L}$ of $\mathrm{CBE}$ was mixed with $1000 \mu \mathrm{L}$ of water, and then $75 \mu \mathrm{L}$ of both $\mathrm{NaNO} 2$ and $\mathrm{AlCl} 3$ was added. The mixture was held for $5 \mathrm{~min}$ at $23^{\circ} \mathrm{C}$, and then $500 \mu \mathrm{L}$ of $1 \mathrm{M}$ $\mathrm{NaOH}$ and $600 \mu \mathrm{L}$ of water were added. The absorbance of the solution was recorded at $510 \mathrm{~nm}$. The result was represented as $\mathrm{mg}$ catechin equivalents per gram dried extract (mg CE/g DW). 


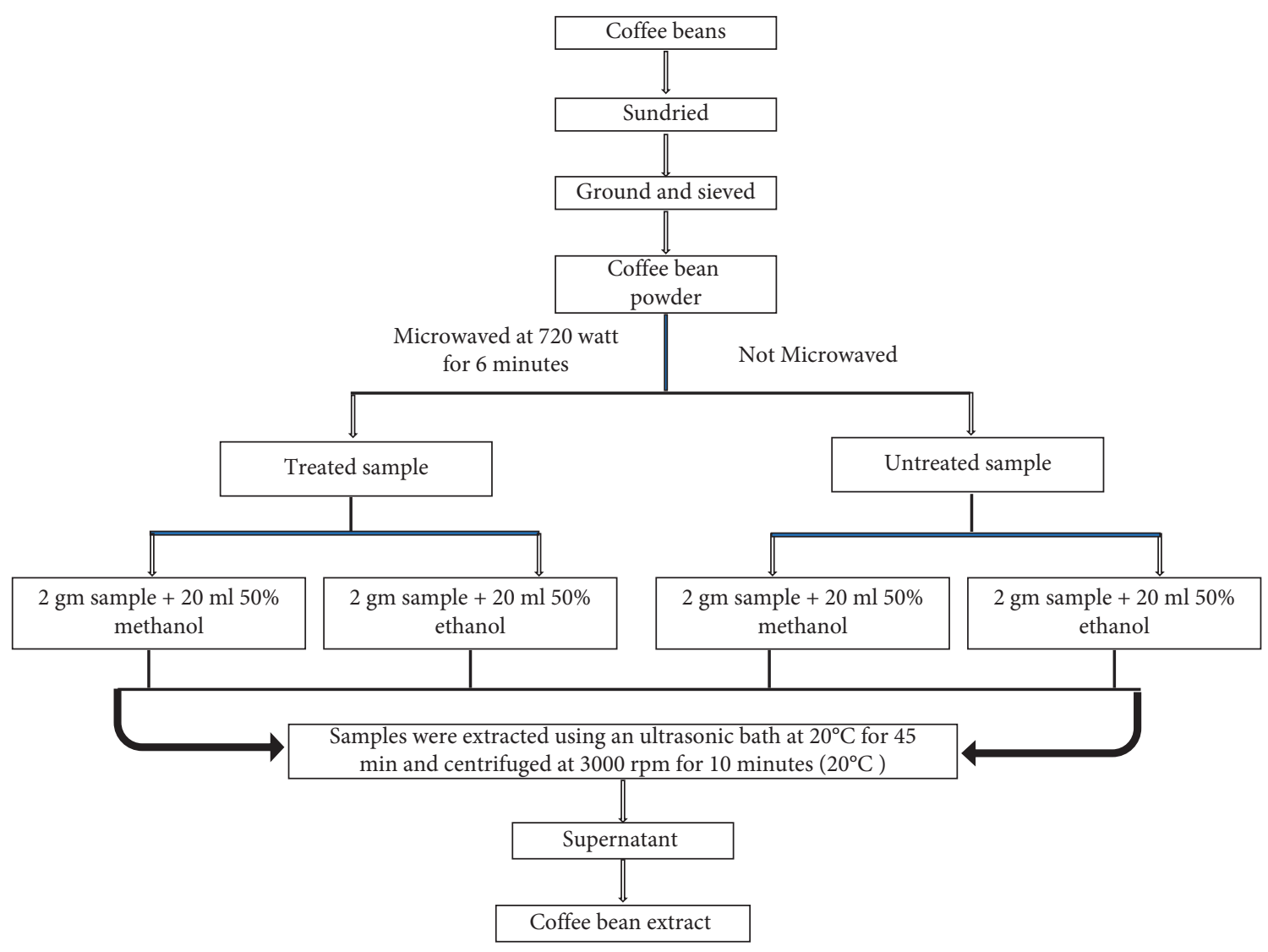

FIGURE 1: Schematic representation of preparation of coffee bean extract.

2.5. DPPH Scavenging. The free radical scavenging capacity of the CBE was determined with 2, 2-diphenyl-1-picrylhydrazyl (DPPH) solution as described by Noreen et al.[34] with slight modification. Briefly, an aliquot of extract $(130 \mu \mathrm{L})$ and $0.1 \mathrm{mM}$ DPPH solution was mixed thoroughly and allowed to stand in a dark place for $30 \mathrm{~min}$. Afterward, the absorbance of the sample and control was recorded at $510 \mathrm{~nm}$. The control was prepared in the same manner except that methanol was used instead of the coffee extract. Methanol was used as a blank. The DPPH scavenging percentage was measured as follows:

$$
\text { DPPH scavenging } \%=\frac{A_{\text {control }}-A_{\text {sample }}}{A_{\text {control }}} \times 100 \text {. }
$$

The outcome was illustrated as $50 \%$ inhibitory concentration $\left(\mathrm{IC}_{50}\right)$ of the $\mathrm{CBE}$.

2.6. Reducing Power. The ferric reducing power of CBE was estimated according to the method of Hayat et al. [35]. Coffee bean extract $(0.5 \mathrm{~mL})$ was mixed thoroughly with $1.25 \mathrm{~mL}$ buffer $(0.2 \mathrm{M}, \mathrm{pH} 6.6)$ and $1.25 \mathrm{~mL}$ of potassium ferricyanide and incubated for $20 \mathrm{~min}$ at $50^{\circ} \mathrm{C}$. Then, $1.25 \mathrm{~mL}$ of trichloroacetic acid (TCA) was added. Afterward, the CBE mixture was centrifuged for $10 \mathrm{~min}$ (at room temperature) at
$3000 \times$ g. An aliquot $(1.25 \mathrm{~mL})$ was taken from the supernatant, to which $1.25 \mathrm{~mL}$ water and $0.25 \mathrm{~mL}$ of ferric chloride were added, respectively. In the end, the absorbance of the sample was measured at $700 \mathrm{~nm}$.

2.7. HPLC Analysis of Phenolic Compounds. In the current study, utilizing HPLC with the method described previously [36], the phenolic (chlorogenic acid, gallic acid, vanillin, salicylic acid, and caffeic acid) compounds in CBE were quantified. In HPLC system Shimadzu, prominence (Kyoto, Japan) equipped with an LC-20AB binary pump, variable Shimadzu SPD-10A UV-Vis detector was used. The column used was Zorbax SB-C18 $(250 \times 4.6 \mathrm{~mm}, 5 \mu \mathrm{m})$ (Agilent, Santa Clara, CA, USA) and the mobile was ( $0.1 \%$ formic acid, A) and $\mathrm{MeOH}(0.1 \%$ formic acid, B). The gradient program was the following: $0 \min 5 \% \mathrm{~B} ; 4 \mathrm{~min} 5 \% \mathrm{~B} ; 20 \mathrm{~min} 73 \% \mathrm{~B} ; 50 \mathrm{~min} 95 \% \mathrm{~B}$; $57 \operatorname{min~} 1 \% \mathrm{~B} ; 58 \mathrm{~min} 1 \% \mathrm{~B} ; 60 \mathrm{~min} 5 \% \mathrm{~B}$; at a low rate of $0.7 \mathrm{~mL} / \mathrm{min}$. The injection volume was $10 \mu \mathrm{L}$, and the detector was set at $280 \mathrm{~nm}$. Compounds were identified by comparing their retention time with those of the standard (Figure 2). All samples were analyzed in duplicate. 


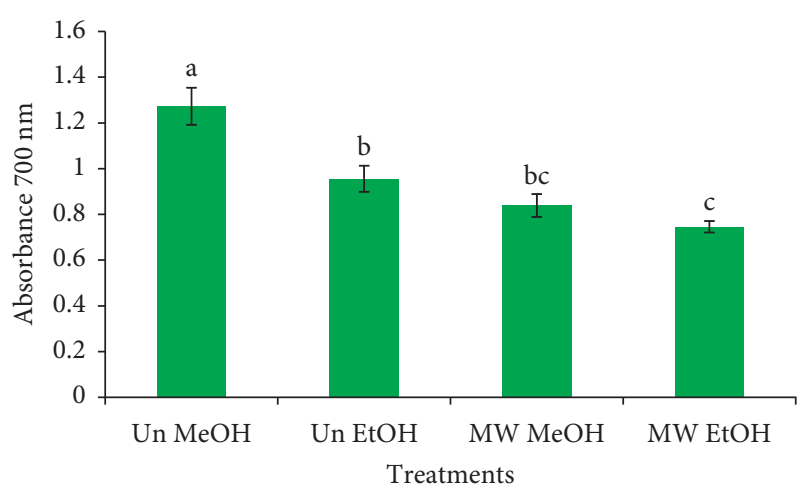

FIGURE 2: Impact of microwave roasting and extraction solvents on the reducing power of coffee beans. Bars with different small letters are significantly different from one another $(p<0.05)$. Un $\mathrm{MeOH}$ : untreated sample extracted with $50 \%$ (v/v) methanol, Un EtOH: untreated sample extracted with 50\% (v/v) ethanol, MW $\mathrm{MeOH}$ : microwave-roasted sample extracted with $50 \%(\mathrm{v} / \mathrm{v})$ methanol, and MW EtOH: microwave-roasted sample extracted with 50\% (v/v) ethanol.

2.8. Statistical Analysis. Each test was performed in triplicate. The results are illustrated as the mean \pm SD (standard deviation). Using SAS statistical software (version 9.2, 2000-2008; SAS Institute Inc., Cary, NC, USA), one-way analysis of variance (ANOVA) was applied to groups, and Duncan's multiple range tests were used to calculate significant differences among the parameters.

\section{Results and Discussion}

3.1. Effect of Microwave Roasting (MW) and Extracting Solvents (ES) on the Total Polyphenols of Coffee Bean Extracts. Figure 3 depicts the effect of MW and ES (ethanol and methanol) on the TPC of untreated (raw) and microwaveroasted coffee beans. In the current study, it was found that the untreated CBE exhibited higher TPC as compared with that of microwave-roasted coffee beans as extracted with both methanol and ethanol. It was found that in the coffee beans extracted with methanol, the TPC of the untreated sample was $40.40 \mathrm{mg}$ GAE/g DW, which was higher than the TPC found in the MW sample (35.15 mg GAE/g DW). Previous studies on the impact of roasting on TPC and antioxidant activity have reported inconsistent findings. In accordance with the current report, another study demonstrated that green coffees (Arabica and Robusta) had higher TPC and possessed enhanced antioxidant activity compounds in comparison to roasted coffees [37]. These results are also in accordance with the findings of Nebesny and Budryn who found that green coffee exhibited a higher antioxidant activity as compared to the conventional and microwave-roasted samples [38]. The degradation, polymerization, and auto-oxidation of the phenolic compounds during roasting process might be the cause of a decrease in their content [39]. In another study, in contradiction of the above mentioned studies, statistically insignificant differences were reported between the TPC of raw and roasted coffee beans [40]. However, during the process of roasting,
Divišet al.[41] reported an upsurge in the TPC of green coffee beans, and Król et al.[19] reported that the highest TPC was determined in coffees roasted under light and medium roasting conditions.

When the extracting solvent was taken into account, it was found that compared to ethanol, the other solvent (methanol) extracted a significantly higher content $(p<0.05)$ of polyphenols from both the untreated and MW coffee beans. The TPC of untreated coffee beans extracted by methanol and ethanol was measured as 40.40 and $36.92 \mathrm{mg}$ GAE/g DW, respectively. The outcomes of this study are in accordance with the findings of Jaiswal et al.[42] who reported the highest TPC in methanolic extract compared to others, that is, water, acetone, and ethanol extracts.

\subsection{Effect of Microwave Roasting (MW) and Extraction Sol-} vents (ES) on the Total Flavonoid Content of Coffee Beans. The TFC of CBE is shown in Figure 4. The MW, as well as ES, showed a similar trend for the TFC of coffee beans as was that for the TPC. Untreated coffee beans and methanol as an ES showed a higher TFC as compared to MW coffee beans and ethanol, respectively. The TFCs of untreated and microwave-roasted coffee beans extracted with ethanol were found as 34.82 and $25.59 \mathrm{mg} \mathrm{CE} / \mathrm{g} \mathrm{DW}$, respectively. When comparing the results of this study to the findings of Ghafoor et al.[43], it was found that roasting has similar effects on other plant materials as he reported a decrease in the TFC of poppy seeds and oil upon roasting in the microwave oven at $720 \mathrm{~W}$ for $5 \mathrm{~min}$. In contrast, Al-Juhaimi et al. [44] indicated that the TFC of apricot kernels was increased by roasting them at $320 \mathrm{~W}, 540 \mathrm{~W}$, but decreased when the microwave power was increased to $720 \mathrm{~W}$. Microwave heating breaks open the cell walls of the plant materials, allowing phytochemicals to be released more easily, and increasing the availability of bioactive materials [45].

Methanol extracted resulted in a significantly $(p<0.05)$ higher total flavonoid content when compared to ethanol. For instance, the TFC of untreated coffee beans as extracted by methanol and ethanol was 39.34 and $34.82 \mathrm{mg} \mathrm{CE} / \mathrm{g} \mathrm{DW}$, respectively. In an earlier study, extraction was done with acetone, water, ethanol, and methanol and highest level of TFC was obtained using methanol as an ES, which corroborates well with the findings of the present study [42]. Polarity is responsible for the extraction of phenolic compounds from solvents. Alkalthamet al. reported higher TPC and TFC in coffee beans and pulp samples extracted with methanol as compared to ethyl acetate [46]. Similarly, in another study conducted on green coffee beans extracted in ethanol and ethyl acetate, the ethyl acetate extract exhibited a lower TPC [47].

\subsection{Effect of Microwave Roasting (MW) and Extraction Sol-} vents (ES) on the DPPH Scavenging of Coffee Beans. The antioxidant activity of the untreated and MW coffee beans was measured using the 2,2-diphenyl-1- picrylhydrazyl (DPPH) radical scavenging method and represented as $50 \%$ inhibitory concentration $\left(\mathrm{IC}_{50}\right)$ of the coffee extract. The results expressed in Figure 5 showed that MW and the ES 


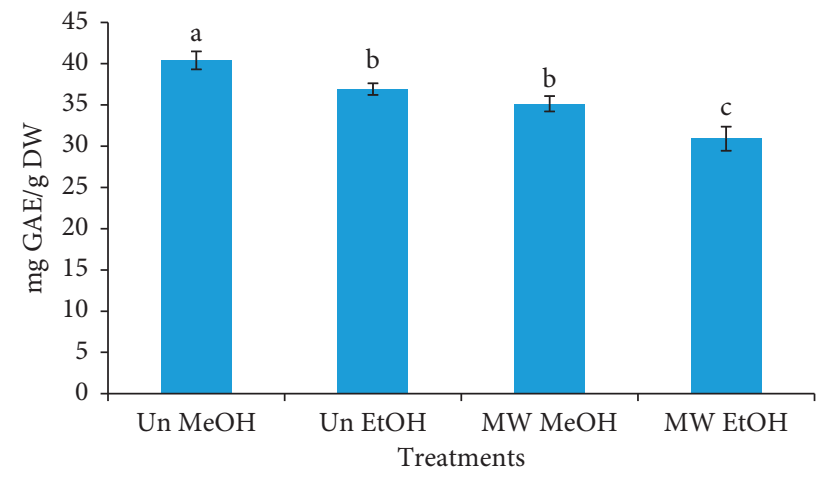

Figure 3: Impact of microwave roasting and extraction solvents on the total polyphenol content of coffee beans. Bars with different small letters are significantly different from one another $(p<0.05)$. Un $\mathrm{MeOH}$ : untreated sample extracted with $50 \%(\mathrm{v} / \mathrm{v}) \mathrm{methanol,} \mathrm{Un} \mathrm{EtOH:}$ untreated sample extracted with 50\% (v/v) ethanol, $\mathrm{MW} \mathrm{MeOH}$ : microwave-roasted sample extracted with 50\% (v/v) methanol, and MW EtOH: microwave-roasted sample extracted with $50 \%(\mathrm{v} / \mathrm{v})$ ethanol.

had a significant $(p<0.05)$ effect on the DPPH scavenging of the coffee beans. In comparison to the MW coffee beans, the untreated samples of CBE exhibited a significantly higher antioxidant activity with lower $\mathrm{IC}_{50}$ values. For example, the obtained $\mathrm{IC}_{50}$ values for untreated and $\mathrm{MW}$ samples as extracted by methanol were 4.13 and $5.68 \mathrm{mg} / \mathrm{mL}$, respectively. Similarly, Doğan et al.[48] found that the roasting of coffee exerted a negative effect on its antioxidant potential. In another study, green (raw) coffee also resulted in a higher antioxidant activity when compared to the conventional and microwave-roasted samples [38]. In contrast, Ludwig et al., [49] stated an upsurge in the DPPH scavenging of the roasted coffee. The DPPH scavenging of some other plant materials like citrus peels and pomace, fennel seeds [45], and apricot kernels [44] was increased by microwave roasting. High-temperature processing is thought to result in an increase of TPC and TFC in the plant materials, which leads to their increased antioxidant activity [50].

In addition, the methanol extracted coffee bean samples had significantly higher antioxidant activity in comparison with their ethanol extracted counterparts. The $\mathrm{IC}_{50}$ values for MR samples extracted using methanol and ethanol were $5.68 \mathrm{mg} / \mathrm{mL}$ and $6.24 \mathrm{mg} / \mathrm{ml}$, respectively. The methanol extraction of coffee silver skin yielded a higher DPPH quenching ability than that extracted with other solvents [46].

\subsection{Effect of Microwave Roasting (MW) and Extraction Sol-} vents (ES) on the Reducing Power of Coffee Beans. The outcome of the effect of MW and ES on the reducing power of coffee beans is described in Figure 2. Untreated coffee beans exhibited higher reducing power (1.237) than that of the microwave-roasted ones (0.839) when extracted with methanol. Extraction solvents also showed a significantly different $(p<0.05)$ effect on the reducing power of coffee beans. It was noted that the reducing power of the untreated coffee beans sample extracted with ethanol (0.956) was less than those extracted with methanol (1.237). The results of antioxidant assays (DPPH scavenging, reducing power) echoed the results of TPC and TFC showing that the antioxidant potential of coffee beans was at least in part due to the polyphenol and flavonoid contents.

A previous study [51] reported a negative trend of the antioxidant capacity of Coffea arabica with increasing roasting degrees, which is in accordance with the results of the present study. Likewise, our findings find support from the observations made with green coffee beans decline that demonstrated a decline in the antioxidant capacity during the roasting process [52]. However, in contrast to our results, when compared to green coffee, Liang et al.[53] reported an increase in the antioxidant capacity of roasted beans. Such inconsistencies could be accredited to the intricacy of the chemical reactions during the roasting process. The plausible reason could be that during the roasting process of coffee beans, some of the bioactive compounds like chlorogenic acids are degraded which in turn could reduce the antioxidant activity of the coffee beans [52]. In addition, such degradations may also result in the release of other bioactive compounds such as hydroxycinnamates and quinic acid, which contribute to increased antioxidant potential [54]. Moreover, the Maillard reaction may also take place due to high temperature during the roasting process, generating a number of compounds, which can contribute to the elevated antioxidant potential of the product [55]. Consequently, all of the substances appearing during roasting process can either compensate for the loss of some compounds or even contribute towards the enhancement in the antioxidant potential [49].

3.5. HPLC Analysis of Phenolic Compounds. The average quantitative data reported in this study (Table 2) show that chlorogenic acid was the major (2.31-2.68\%) phenolic compound found in all the coffee samples (untreated and microwave-roasted) followed by caffeic acid $(0.997-1.18 \%)$. Vanillin demonstrated the lowest $(0.118-0.187 \%)$ phenolic compound found in the coffee bean samples. Typical chromatogram of HPLC for standards and the sample is shown in Figure 6. An insignificant influence of $\mathrm{MW}$ and ES on the phenolic compounds of the coffee beans was observed. There is no 


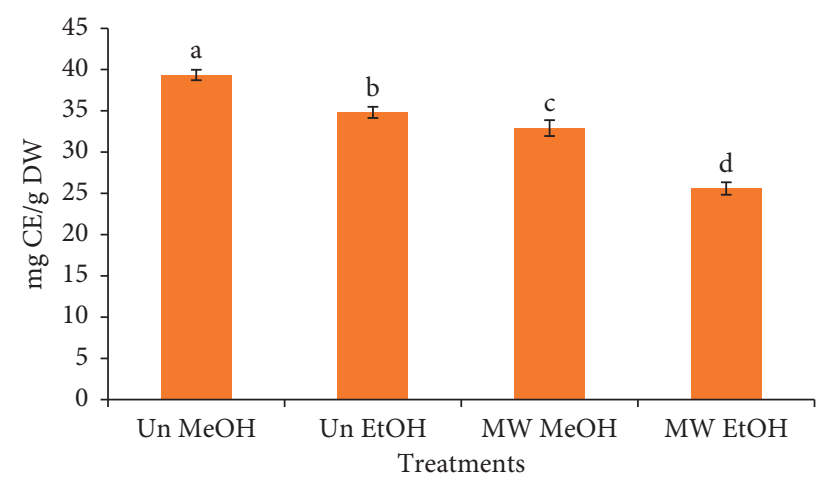

FIGURE 4: Impact of microwave roasting and extraction solvents on the total flavonoid content of coffee beans. Bars with different small letters are significantly different from one another $(p<0.05)$. Un $\mathrm{MeOH}$ : untreated sample extracted with $50 \%(\mathrm{v} / \mathrm{v}) \mathrm{methanol,} \mathrm{Un} \mathrm{EtOH:}$ untreated sample extracted with 50\% (v/v) ethanol, MW MeOH: microwave-roasted sample extracted with 50\% (v/v) methanol, and MW EtOH: microwave-roasted sample extracted with $50 \%(\mathrm{v} / \mathrm{v})$ ethanol.

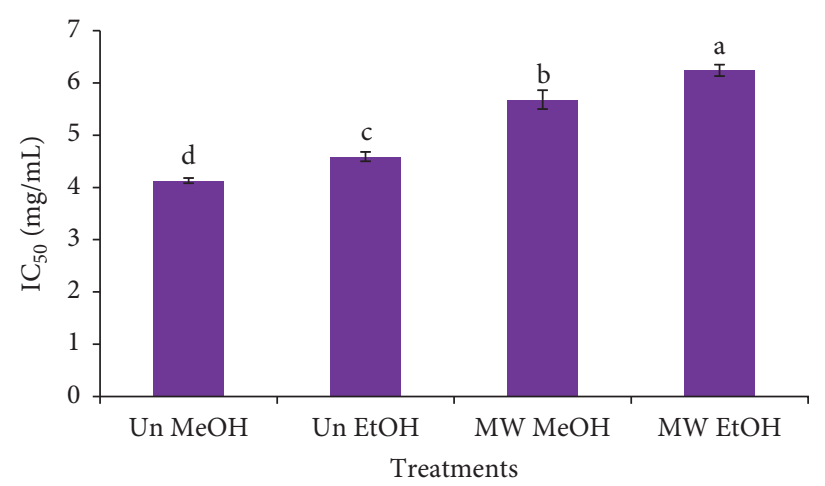

FIGURE 5: Impact of microwave roasting and extraction solvents on the DPPH scavenging of coffee beans. Bars with different small letters are significantly different from one another $(p<0.05)$. Un MeOH: untreated sample extracted with 50\% (v/v) methanol, Un EtOH: untreated sample extracted with 50\% (v/v) ethanol, MW MeOH: microwave-roasted sample extracted with 50\% (v/v) methanol, and MW EtOH: microwave-roasted sample extracted with $50 \%(\mathrm{v} / \mathrm{v})$ ethanol.

TABLE 2: Concentration of phenolics (gm/100 gm) dry weight basis.

\begin{tabular}{lccr}
\hline Sample & Chlorogenic acid & Caffeic acid & Vanillin \\
\hline Untreated MeOH & $2.31 \pm 0.37$ & $0.997 \pm 0.33$ & $0.118 \pm 0.65$ \\
Untreated EtOH & $2.31 \pm 0.58$ & $0.997 \pm 0.67$ & $0.166 \pm 0.27$ \\
MW MeOH & $2.68 \pm 0.63$ & $1.18 \pm 0.91$ & $0.187 \pm 0.63$ \\
MW EtOH & $2.55 \pm 0.87$ & $1.09 \pm 0.65$ & $0.166 \pm 0.87$ \\
\hline
\end{tabular}

Results are expressed as mean $\pm \mathrm{SD}$.

significant difference between the untreated methanolic $(0.997-2.31 \mathrm{~g} / 100 \mathrm{~g})$ or ethanolic $(0.997-2.31 \mathrm{~g} / 100 \mathrm{~g})$ extraction and microwave methanolic (0.187-2.68 g/ $100 \mathrm{~g})$ or microwave ethanolic (0.166-2.55 g/100 g) treatments on the phenolic compounds. Similarly, the individual phenolic compounds, chlorogenic acid, caffeic acid, and vanillin, have close similarity in concentrations of all extraction and treatment methods (Table 2). Traditional heating at a high temperature of $120^{\circ} \mathrm{C}$ even for a short time results in the loss of $15-36 \%$ of the bioactive compounds [56]. Similar results have been reported in Ethiopian and Ugandan with roasted coffee where chlorogenic acid was present in the highest concentrations [44]. In another study, chlorogenic acid was reported as the major phenolic acid in spent coffee grounds extract as confirmed by HPLC [45]. Higher chlorogenic acid levels were extracted by multistep whole coffee fruit extracts than by the single-step extract [46]. 


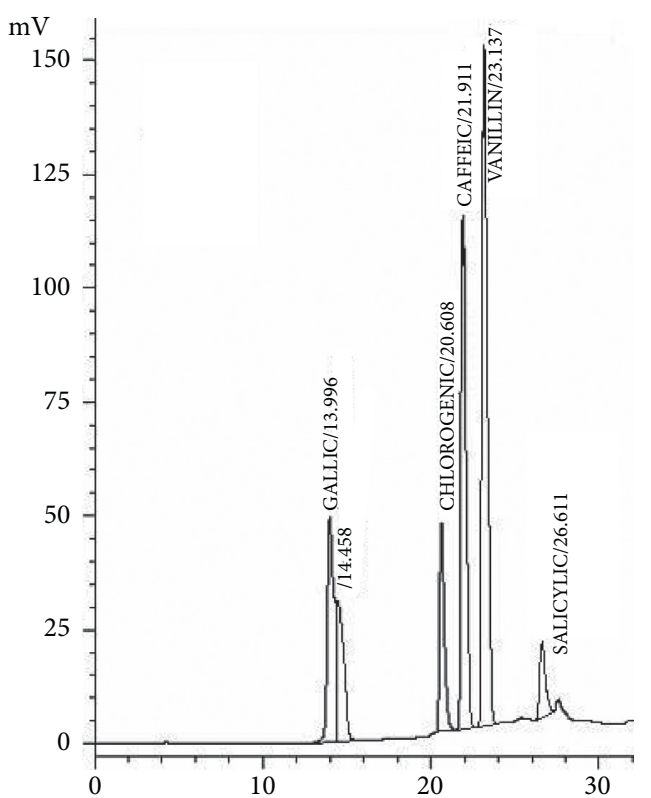

(a)

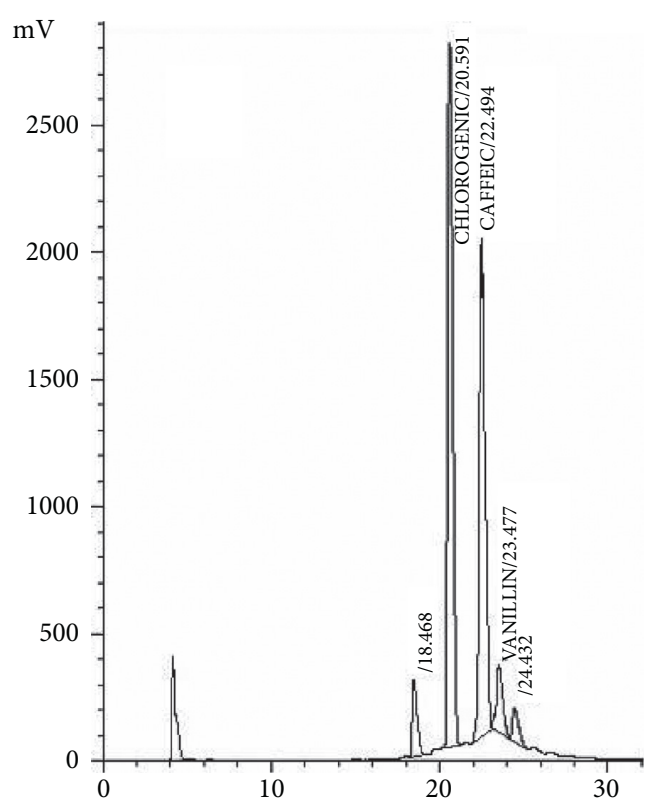

(b)

Figure 6: Typical HPLC chromatogram of standards (a) and coffee sample (b).

\section{Conclusions}

Roasting is an important step in the processing of coffee before it is consumed as a beverage. Therefore, the effects of MW and ES on the TPC, TFC, and antioxidant activity of coffee beans were evaluated. Compared to the untreated coffee beans, the MR coffee beans showed significantly lower TPC, TFC, and antioxidant activity. Similarly, the methanol showed better results compared to ethanol for both untreated and microwaveroasted samples. Irrespective of the ES and MW treatment, all major and important phenolic compounds were present with no significant difference. Chlorogenic acid is the key phenolic acid in untreated, microwave, methanol, and ethanolic extracts and can reap health benefits. This information might be helpful for the processing of coffee beans and can be exploited by the beverage industry. There are certain inconsistencies in the findings as compared to previous studies, but these can be attributed to factors such as method of extraction, microwave treatment, and climatic conditions. Moreover, future studies need to focus on the underlying mechanism of action of roasting on the studied parameters.

\section{Data Availability}

Data used to support the findings are included within the text.

\section{Conflicts of Interest}

The authors declare no conflicts of interest.

\section{Acknowledgments}

The authors extend their appreciation to the Deanship of Scientific Research at King Saud University for funding this work through research group no. RG-1441-360.

\section{References}

[1] M. L. G. Bizzo, A. Farah, J. A. Kemp, and L. B. Scancetti, "Highlights in the history of coffee science related to health," in Coffee in Health and Disease Prevention, pp. 11-17, Elsevier, Amsterdam, Netherlands, 2015.

[2] J. A. Vignoli, D. G. Bassoli, and M. T. Benassi, "Antioxidant activity, polyphenols, caffeine and melanoidins in soluble coffee: the influence of processing conditions and raw material," Food Chemistry, vol. 124, no. 3, pp. 863-868, 2011.

[3] B. M. Gichimu, "Variation and association of cup quality attributes and resistance to coffee berry disease in coffea arabica L. composite cultivar, ruiru 11," African Journal of Horticulture Science, vol. 7, pp. 22-35, 2013.

[4] FAO, FAO Statistical Pocketbook: 2015-Coffee, Food Agriculture Organization, Rome, Italy, 2016.

[5] IMF, The Federal Democratic Republic of Ethiopia: Selected Issues and Statistical Appendix, International Monetary Fund, Washington, D.C., USA, 2006.

[6] S. E. George, K. Ramalakshmi, and L. J. Mohan Rao, "A perception on health benefits of coffee," Critical Reviews in Food Science and Nutrition, vol. 48, no. 5, pp. 464-486, 2008.

[7] J. H. O’Keefe, S. K. Bhatti, H. R. Patil, J. J. DiNicolantonio, S. C. Lucan, and C. J. Lavie, "Effects of habitual coffee consumption on cardiometabolic disease, cardiovascular health, and all-cause mortality," Journal of the American College of Cardiology, vol. 62, no. 12, pp. 1043-1051, 2013.

[8] Z. Zhang, G. Hu, B. Caballero, L. Appel, and L. Chen, "Habitual coffee consumption and risk of hypertension: a systematic review and meta-analysis of prospective observational studies," American Journal of Clinical Nutrition, vol. 93, no. 6, pp. 1212-1219, 2011.

[9] O. J. Kennedy, P. Roderick, R. Buchanan, J. A. Fallowfield, P. C. Hayes, and J. Parkes, "Coffee, including caffeinated and decaffeinated coffee, and the risk of hepatocellular carcinoma: a systematic review and dose-response meta-analysis," $B M J$ Open, vol. 7, no. 5, Article ID e013739, 2017. 
[10] R. Poole, O. J. Kennedy, P. Roderick, J. A. Fallowfield, P. C. Hayes, and J. Parkes, "Coffee consumption and health: umbrella review of meta-analyses of multiple health outcomes," BMJ, vol. 359, p. j5024, 2017.

[11] J. V. Higdon and B. Frei, "Coffee and health: a review of recent human research," Critical Reviews in Food Science and $\mathrm{Nu}$ trition, vol. 46, no. 2, pp. 101-123, 2006.

[12] E. Lopez-Garcia, R. M. van Dam, W. C. Willett et al., "Coffee consumption and coronary heart disease in men and women: a prospective cohort study," Circulation, vol. 113, no. 17, pp. 2045-2053, 2006.

[13] S. N. Bhupathiraju, A. Pan, V. S. Malik et al., "Caffeinated and caffeine-free beverages and risk of type 2 diabetes," American Journal of Clinical Nutrition, vol. 97, no. 1, pp. 155-166, 2013.

[14] C. Manach, G. Williamson, C. Morand, A. Scalbert, and C. Rémésy, "Bioavailability and bioefficacy of polyphenols in humans. I. review of 97 bioavailability studies," American Journal of Clinical Nutrition, vol. 81, no. 1 Suppl, pp. 230S242S, 2005.

[15] Y.-F. Chu, Coffee: Emerging Health Effects and Disease Prevention, John Wiley \& Sons, Hoboken, NJ, USA, 2012.

[16] M. N. Clifford, "Chlorogenic acids and other cinnamates-nature, occurrence, dietary burden, absorption and metabolism," Journal of the Science of Food and Agriculture, vol. 80, no. 7, pp. 1033-1043, 2000.

[17] Y. Narita and K. Inouye, "Inhibitory effects of chlorogenic acids from green coffee beans and cinnamate derivatives on the activity of porcine pancreas $\alpha$-amylase isozyme I," Food Chemistry, vol. 127, no. 4, pp. 1532-1539, 2011.

[18] N. C. Bicho, A. E. Leitão, J. C. Ramalho, N. B. de Alvarenga, and F. C. Lidon, "Impact of roasting time on the sensory profile of arabica and robusta coffee," Ecology of Food and Nutrition, vol. 52, no. 2, pp. 163-177, 2013.

[19] K. Król, M. Gantner, A. Tatarak, and E. Hallmann, "The content of polyphenols in coffee beans as roasting, origin and storage effect," European Food Research and Technology, vol. 246, no. 1, pp. 33-39, 2020.

[20] C. S. G. Kitzberger, M. B. d. S. Scholz, and M. d. T. Benassi, "Bioactive compounds content in roasted coffee from traditional and modern Coffea arabica cultivars grown under the same edapho-climatic conditions," Food Research International, vol. 61, pp. 61-66, 2014.

[21] P. Parras, M. Martineztome, A. Jimenez, and M. Murcia, "Antioxidant capacity of coffees of several origins brewed following three different procedures," Food Chemistry, vol. 102, no. 3, pp. 582-592, 2007.

[22] A. N. Gloess, B. Schönbächler, B. Klopprogge et al., "Comparison of nine common coffee extraction methods: instrumental and sensory analysis," European Food Research and Technology, vol. 236, no. 4, pp. 607-627, 2013.

[23] M. D. del Castillo, J. M. Ames, and M. H. Gordon, "Effect of roasting on the antioxidant activity of coffee brews," Journal of Agricultural and Food Chemistry, vol. 50, no. 13, pp. 36983703, 2002.

[24] J.-K. Moon, H. S. Yoo, and T. Shibamoto, "Role of roasting conditions in the level of chlorogenic acid content in coffee beans: correlation with coffee acidity," Journal of Agricultural and Food Chemistry, vol. 57, no. 12, pp. 5365-5369, 2009.

[25] M. Alkaltham, N. Musa Özcan, A. M. Uslu, M. Salamatullah, and K. Hayat, "Effect of microwave and oven roasting methods on total phenol, antioxidant activity, phenolic compounds, and fatty acid compositions of coffee beans," Journal of Food Processing and Preservation, vol. 44, no. 11, Article ID e14874, 2020.
[26] L. C. Mendes, H. C. de Menezes, M. Aparecida, and A. P. da Silva, "Optimization of the roasting of robusta coffee (C. canephora conillon) using acceptability tests and RSM," Food Quality and Preference, vol. 12, no. 2, pp. 153-162, 2001.

[27] A. C. d. S. Caetano, C. R. d. Araújo, V. L. A. G. d. Lima, M. I. S. Maciel, and E. d. A. Melo, "Evaluation of antioxidant activity of agro-industrial waste of acerola (Malpighia emarginata D.C.) fruit extracts," Ciência e Tecnologia de Alimentos, vol. 31, no. 3, pp. 769-775, 2011.

[28] E. N. Frankel and A. S. Meyer, "The problems of using onedimensional methods to evaluate multifunctional food and biological antioxidants," Journal of the Science of Food and Agriculture, vol. 80, no. 13, pp. 1925-1941, 2000.

[29] U. Zlotek, M. Karas, U. Gawlik-Dziki, U. Szymanowska, B. Baraniak, and A. Jakubczyk, "Antioxidant activity of the aqueous and methanolic extracts of coffee beans (Coffea arabica L.)," Acta Scientiarum Polonorum, Technologia Alimentaria, vol. 15, no. 3, pp. 281-288, 2016.

[30] M. Herrero, A. Cifuentes, and E. Ibañez, "Sub-and supercritical fluid extraction of functional ingredients from different natural sources: plants, food-by-products, algae and microalgae: a review," Food Chemistry, vol. 98, no. 1, pp. 136-148, 2006.

[31] P. Koseoglu Yilmaz and U. Kolak, "SPE-HPLC determination of chlorogenic and phenolic acids in coffee," Journal of Chromatographic Science, vol. 55, no. 7, pp. 712-718, 2017.

[32] A. A. Rahim, S. Nofrizal, and B. Saad, "Rapid tea catechins and caffeine determination by HPLC using microwave-assisted extraction and silica monolithic column," Food Chemistry, vol. 147, pp. 262-268, 2014.

[33] K. Hayat, "Impact of drying methods on the functional properties of peppermint (Mentha piperita L.) leaves," Science Letter, vol. 8, pp. 36-42, 2020.

[34] H. Noreen, N. Semmar, M. Farman, and J. S. O. McCullagh, "Measurement of total phenolic content and antioxidant activity of aerial parts of medicinal plant coronopus didymus," Asian Pacific Journal of Tropical Medicine, vol. 10, no. 8, pp. 792-801, 2017.

[35] K. Hayat, X. Zhang, H. Chen, S. Xia, C. Jia, and F. Zhong, "Liberation and separation of phenolic compounds from citrus Mandarin peels by microwave heating and its effect on antioxidant activity," Separation and Purification Technology, vol. 73, no. 3, pp. 371-376, 2010.

[36] J. Santos, M. B. P. P. Oliveira, E. Ibáñez, and M. Herrero, "Phenolic profile evolution of different ready-to-eat baby-leaf vegetables during storage," Journal of Chromatography A, vol. 1327, pp. 118-131, 2014.

[37] A. Bobková, M. Hudáček, S. Jakabová et al., "The effect of roasting on the total polyphenols and antioxidant activity of coffee," Journal of Environmental Science and Health, Part B, vol. 55, no. 5, pp. 495-500, 2020.

[38] E. Nebesny and G. Budryn, "Antioxidative activity of green and roasted coffee beans as influenced by convection and microwave roasting methods and content of certain compounds," European Food Research and Technology, vol. 217, no. 2, pp. 157-163, 2003.

[39] P. Wongsa, N. Khampa, S. Horadee, J. Chaiwarith, and N. Rattanapanone, "Quality and bioactive compounds of blends of Arabica and robusta spray-dried coffee," Food Chemistry, vol. 283, pp. 579-587, 2019.

[40] A. E. Muñoz, S. S. Hernández, A. R. Tolosa, S. P. Burillo, and M. Olalla Herrera, "Evaluation of differences in the antioxidant capacity and phenolic compounds of green and roasted 
coffee and their relationship with sensory properties," $L W T$, vol. 128, Article ID 109457, 2020.

[41] P. Diviš, J. Pořízka, and J. Krŕkala, "The effect of coffee beans roasting on its chemical composition," Potravinarstvo, vol. 13, no. 1, 2019.

[42] A. K. Jaiswal, G. Rajauria, N. Abu-ghannam, and S. Gupta, "Effect of different solvents on polyphenolic content, antioxidant capacity and antibacterial activity of Irish York cabbage," Journal of Food Biochemistry, vol. 36, no. 3, pp. 344-358, 2012.

[43] K. Ghafoor, M. M. Özcan, F. AL-Juhaimi, E. E. Babiker, and G. J. Fadimu, "Changes in quality, bioactive compounds, fatty acids, tocopherols, and phenolic composition in oven-and microwave-roasted poppy seeds and oil," LWT, vol. 99, pp. 490-496, 2019.

[44] F. Al Juhaimi, M. Musa Özcan, K. Ghafoor, and E. E. Babiker, "The effect of microwave roasting on bioactive compounds, antioxidant activity and fatty acid composition of apricot kernel and oils," Food Chemistry, vol. 243, pp. 414-419, 2018.

[45] K. Hayat, S. Abbas, S. Hussain, S. A. Shahzad, and M. U. Tahir, "Effect of microwave and conventional oven heating on phenolic constituents, fatty acids, minerals and antioxidant potential of fennel seed," Industrial Crops and Products, vol. 140, Article ID 111610, 2019.

[46] M. S. Alkaltham, A. Salamatullah, and K. Hayat, "Determination of coffee fruit antioxidants cultivated in Saudi Arabia under different drying conditions," Journal of Food Measurement and Characterization, vol. 14, no. 3, pp. 1306-1313, 2020.

[47] É. R. Oliveira, R. F. Silva, P. R. Santos, and F. Queiroz, "Potential of alternative solvents to extract biologically active compounds from green coffee beans and its residue from the oil industry," Food and Bioproducts Processing, vol. 115, pp. 47-58, 2019.

[48] M. Doğan, D. Asian, V. Gurmeric, A. Ozgur, and M. G. Sarac, "Powder caking and cohesion behaviours of coffee powders as affected by roasting and particle sizes: principal component analyses (PCA) for flow and bioactive properties," Powder Technology, vol. 344, pp. 222-232, 2019.

[49] I. A. Ludwig, J. Bravo, M. P. De Peña, and C. Cid, "Effect of sugar addition (torrefacto) during roasting process on antioxidant capacity and phenolics of coffee," LWT-Food Science and Technology, vol. 51, no. 2, pp. 553-559, 2013.

[50] S.-N. Lou, Y.-C. Lai, J.-D. Huang, C.-T. Ho, L.-H. A. Ferng, and Y.-C. Chang, "Drying effect on flavonoid composition and antioxidant activity of immature kumquat," Food Chemistry, vol. 171, pp. 356-363, 2015.

[51] S. E. W. Opitz, B. A. Goodman, M. Keller et al., "Understanding the effects of roasting on antioxidant components of coffee brews by coupling on-line ABTS assay to high performance size exclusion chromatography," Phytochemical Analysis, vol. 28, no. 2, pp. 106-114, 2017.

[52] D. Perrone, A. Farah, and C. M. Donangelo, "Influence of coffee roasting on the incorporation of phenolic compounds into melanoidins and their relationship with antioxidant activity of the brew," Journal of Agricultural and Food Chemistry, vol. 60, no. 17, pp. 4265-4275, 2012.

[53] N. Liang, W. Xue, P. Kennepohl, and D. D. Kitts, "Interactions between major chlorogenic acid isomers and chemical changes in coffee brew that affect antioxidant activities," Food Chemistry, vol. 213, pp. 251-259, 2016.

[54] F. Wei and M. Tanokura, "Chemical changes in the components of coffee beans during roasting," in Coffee in Health and Disease Prevention, pp. 83-91, Elsevier, Amsterdam, Netherlands, 2015.

[55] S. Pastoriza and J. A. Rufián-Henares, "Contribution of melanoidins to the antioxidant capacity of the Spanish diet," Food Chemistry, vol. 164, pp. 438-445, 2014.

[56] L.-F. Wang, D.-M. Kim, and C. Y. Lee, "Effects of heat processing and storage on flavanols and sensory qualities of green tea beverage," Journal of Agricultural and Food Chemistry, vol. 48, no. 9, pp. 4227-4232, 2000. 